\title{
Entre a repressão, a prevenção e a "assistência": uma análise de um cur- so de capacitação de policiais atuantes nas Unidades de Polícia Pacificadora do Rio de Janeiro
}

\author{
Fabiano Dias Monteiro \\ Doutor em Antropologio Cultural (PPGSA/UFR)). É Mestre em Sociologio pelo (PPGSA/UFRJ) e Bacharel em ciêncios Sociais (ICHF) \\ UFF). Foi Bolsisto PDR da Fundação de Amparo ò Pesquiso do Rio de janeiro entre os anos de 2011-2014 e atualmente é Profes- \\ sor Adjunto do Departamento de Geografia e Políticas Públicas do IEAR do Universidade Federal Fluminense.

\section{Jonas Pereira Araujo} \\ Graduado em ciências Sociais pela Universidade do Estado do Rio de Janeiro - UERJ, e Mestrado pela Pontifício Universidade Católi- \\ ca do Rio de Janeiro - PPGCIS/PUC-Rio, tendo desenvolvido uma pesquisa sobre "Controle externo, participação e accountability no \\ Ouvidoria das UPPS". Desde março de 2018 é aluno de doutorado no PPGCIS/PUC-Rio.
}

\begin{abstract}
Data de recebimento: $15 / 01 / 2017$
Data de aprovação: 28/09/2018

DOI: 10.31060/rbsp.2018.v12.n1.898
\end{abstract}

\section{Resumo}

o presente artigo busca realizar uma reflexão acerco do experiêncio do Curso de Cidadanio e Acesso ò Rede de Proteção Social para policiais atuantes em UPPS - iniciativa de copacitação policial desenvolvida pela Polício Militar do Rio de Janeiro e a ONG Vivo Rio. o curso buscovo ampliar o nível de conhecimento dos militares acerco do rede de proteção social e promover a aproximação entre policiais e operadores locais dos programas de atenção social. No condição de integrantes da equipe técnica que participou da concepção e implementação do curso, buscamos neste artigo identificar os desafios que se apresentaram durante sua execução, e como material de apoio à nosso análise nos utilizamos de dois questionários (um circulodo no início do curso e outro oo final) que tratovam de temas como: fomiliaridade dos policiais com a realidade das comunidades; nível de integração policiais-rede de proteção social; e percepções acerca do trabalho nas UPPS. o que podemos afirmar, a partir da análise empreendida, é que parece haver ainda um longo cominho a percorrer, no que diz respeito à integração das ações policiais às do rede proteção social.

\section{Palavras -Chave}

Rede de proteção social. Policiomento de proximidade. Formação policial. Direitos Humanos. Unidades de Polícia Pacificadora. 


\begin{abstract}
Between repression, prevention and "assistance": an analysis of a training course for police officers working in the Pacifying Police Units of Rio de Janeiro

The present article seeks the reflection on the experience of the Course of Citizenship and Access to the Social Protection Network for policemen working in UPPS - a police training initiative developed by the Rio de Janeiro Military Police and the NGO Viva Rio. The course aimed to increase the level of knowledge of the military about the social protection network and to promote the rapprochement between police and local operators of social care programs. As members of the technical team that participated in the conception and implementation of the course, we sought in this article to identify the challenges that arose during its execution, and as material to support our analysis we used two questionnaires (one used at the beginning of the course and another at the end) that treated themes such as: the fomiliarity of the police with the reality of the communities; level of integration of the police social protection network; and perceptions about work in UPPS. What we can affirm, from the undertaken analysis, is that there still seems to be a long way to go, with regard to the integration of police actions to those of the social protection network.
\end{abstract}

\title{
Keywords
}

Social protection network. Community policing. Police training. Human rights. Pacifying Police Units. 


\section{INTRODUÇÃO}

0

presente artigo tem por objetivo realizar uma reflexáo acerca da experiência do Curso de Cidadania e Acesso à Rede de Proteção Social para policiais atuantes em UPPs, a saber, uma iniciativa de capacitaçáo de policiais desenvolvida pela Coordenadoria de Polícia Pacificadora (CPP) da Polícia Militar do Rio de Janeiro e a ONG Viva Rio, tendo financiamento da Igreja da Noruega e do Programa de Fomento da Agência Australiana para Desenvolvimento Internacional (AUSAID).

O curso foi concebido e implementado entre os anos de 2013 e 2014, tendo como meta a capacitaçáo de 200 policiais militares lotados nas Unidades de Polícia Pacificadora (UPPs) de 38 diferentes territórios da capital fluminense e da Região Metropolitana.

Sua formulaçãa inicial buscava ampliar o nível de conhecimento dos militares acerca da rede de proteçáo social (serviços de assistência social, programas de desenvolvimento comunitário, rede básica de saúde, etc.), bem como promover a aproximaçáo entre policiais e os operadores locais dos programas de atençáo social, tendo em vista a centralidade da estratégia do policiamento de proximidade no projeto das UPPs.

$\mathrm{Na}$ condição de integrantes da equipe técni$\mathrm{ca}^{1}$ que participou da concepçáo e implementação do curso, buscamos neste artigo realizar um exercício de transformaçáo do "familiar em exótico" (DAMATTA, 2000), procurando identificar os desafios que se apresentaram durante sua execuçáa. Entre eles: (a) os dilemas vividos no processo de formaçáo, diante da indefiniçáo do nível de discricionariedade dos policiais, no ambiente das UPPs; (b) a falta de comunicação entre a Polícia Militar do Rio de Janeiro e os órgáos componentes da chamada "rede de proteçáo social"; (c) a pouca vivencia dos policiais junto à realidade das comunidades onde estavam atuando; e (d) o elevado grau de desconhecimento dos policiais diante dos propósitos da experiência na

1 Aproveitamos para agradecer aos demais membros da equipe que durante o processo de trabalho nos auxiliaram das mais diversas formas a compreender melhor o que víamos e o que fazíamos. Lembramos em especial de Sandro Costo Santos, Cel. Ubiraton de Oliveira Ângelo, Cel. Gilbert Rodrigues, Lidiane Malanquini Magacho, Paloma Henriques Maricato, Laís Martins Costo Araujo. 
qual estavam inseridos.

A princípio, nosso interesse esteve voltado para uma reflexão crítica que pudesse produzir ajustes a versóes futuras do curso, imaginando uma sobrevida do projeto das UPPs que não se confirmou. Apenas num segundo momento, a experiência ganhou objetivos e contornos acadêmicos.

Como material de pesquisa nos utilizamos da análise de dois questionários (um circulado no início do curso e outro ao final), cada qual com aproximadamente 30 questóes, que tratavam de cinco eixos temáticos: I) perfil socioeconômico dos policiais; II) familiaridade dos policiais com a realidade das comunidades; III) nível de integraçáa dos policiais com a rede de proteçáo social; IV) expectativas em relaçáo à experiência em curso e avaliação das aulas; e V) percepçóes acerca do trabalho nas UPPs. O Curso contou com a participaçáo de 218 policiais lotados em 38 unidades, além de policiais da Força Nacional de Segurança, lotados na favela do Santo Amaro. Foram analisados 178 questionários iniciais e 195 questionários finais.

Além dos questionários foram observadas as reuniôes semanais promovidas junto aos monitores das aulas, bem como o acompanhamento in loco de algumas sessôes. Foram também analisados os relatórios de visitas técnicas produzidos pelos alunos, a partir de uma "atividade de campo" que os mesmos desenvolviam junto a órgáos da rede de proteçáo social (Centros de Referência de Assistência Social; Centros de Defesa da Mulher; Unidades de Saúde e afins).

Desta forma, o artigo apresenta-se dividido da seguinte forma: (a) uma apreciaçáo da conjuntura política que viabilizou o projeto das UPPs; (b) uma análise crítica acerca dos modelos de formaçáo policial e sua incompatibilidade com as estratégias de policiamento de proximidade; (c) os movimentos de aproximaçáo entre a ONG Viva Rio e a Polícia Militar, no processo de implementaçáo do curso; $\mathrm{e}$, finalmente, (d) o perfil social e profissional dos participantes e os desafios encontrados no processo de integraçáo com rede de proteçáo social.

\section{O cenário da segurança pública no Rio de Janeiro e a implementação das UPPs I}

No dia primeiro de janeiro de 2011, o Governador do Estado do Rio de Janeiro, Sérgio Cabral, tomava posse para a execuçáo de seu segundo mandato. Da tribuna do Plenário Barbosa Lima Sobrinho (Assembleia Legislativa) se confraternizou com familiares, deputados, senadores, membros do judiciário e das Forças Armadas. Lembrou dos avanços de sua gestão, empreendidos na economia, nas finanças e em outros serviços fundamentais.

Em meio à celebraçáa, um momento de inflexão: Cabral recorda a trágica morte do jornalista Tim Lopes, executado por traficantes do Morro do Alemáo, durante a realizaçáo de uma reportagem investigativa, em 2002.

O governador relembra dos dias de "terror" vividos na cidade do Rio de Janeiro, fazendo uma digressão sobre a situaçáo da segurança pública no estado, na primeira década desse século.

A violência, assim, assume um lugar de contraponto no discurso do governador. Uma lacuna a ser preenchida, em meio a uma administração de inegáveis e significativos feitos, segundo ele. Se o controle do crime e da violência náo podia, finalmente, ser tomado como realizaçáo, 
seria tomado como desafio e o discurso ganha feições de campanha:

Este é um compromisso meu com o povo do Estado do Rio de Janeiro. Quero dizer a V.Exas. que temos muitos temas pela frente, temos muitos desafios pela frente, naárea dos Transportes, da Agricultura, do Meio Ambiente, do Saneamento, da Infraestrutura, da Saúde, da Educação, do calendário fantástico que conquistamos de eventos e investimentos. Mas tudo isso perde peso e importância enquanto nós tivermos um bairro, uma comunidade dominada pelo poder paralelo. Por isso, reafirmo aqui, diante das senhoras e senhores, que em 2014 não haverá uma comunidade, um bairro do nosso Estado dominado pelo poder paralelo, seja miliciano, seja traficante (CABRAL, 2011) (Grifos nossos).

Provavelmente sem imaginar os rumos da administraçáo pública do Rio de Janeiro (e da própria carreira política), Cabral, ao encerrar seu discurso de posse, lançou mão do que viria ser um de seus principais "trunfos" políticos: a ocupaçáo permanente de favelas cariocas pela Polícia Militar, aludindo mais precisamente à sequência do programa das Unidades de Polícia Pacificadora (UPPs), iniciado em dezembro de 2008.

Em primeiro lugar, vale destacar as dificuldades na definiçáo dos marcos institucionais das UPPs. Há relativo consenso de que estas nunca teriam se constituído, propriamente, numa "política pública”, na acepçáo de uma açáo do Estado com etapas de planejamento, implementaçáo, gestáo e avaliaçáo claramente definidas (MACHADO DA SILVA, 2010; LIPSKY, 1969).

A primeira UPP foi instalada no Morro Santa Marta (zona sul), em dezembro de 2008, sendo seguida pelas unidades do Jardim Batan e da
Cidade de Deus (ambas na zona oeste).

É plausível supor que a iniciativa possa ter raízes nas açōes de segurança do próprio estado do Rio de Janeiro. Há de se lembrar que, no início da década de 2000 (no governo de Anthony Garotinho), foram implementados os Grupamentos de Policiamento em Áreas Especiais (GPAEs), que pouco diferiam das UPPs, no que diz respeito à estrutura e funcionamento.

Os GPAEs também se constituíam em um programa de policiamento comunitário em favelas, marcado pela ocupaçáo permanente e que preconizava a metodologia de resoluçáo de problemas (problem solving), orientada para a prevençáo do crime e para a repressáo de traficantes armados.

Segundo Monteiro, Araujo e Santos (2015), há, entre gestores e pesquisadores do tema, a memória de que o programa GPAE tenha se inspirado, no limite, na experiência do cease fire de Boston (EUA), na década de 1990, cujas diretrizes eram:

Originally developed by the Boston (Mass.) Police Department's Youth Violence Strike Force, Operation Ceasefire is a problem-solving police strategy that seeks to reduce gang violence, illegal gun possession, and gun violence in communities (NIJ, 2011).

Lembremos ainda que a associação entre as UPPs e os GPAEs, tende a nos remeter aos "primórdios" do policiamento comunitário no Rio de Janeiro, ainda nos anos 1980/90, e mais, especificamente, à passagem do Cel. Carlos Magno Nazareth Cerqueira pelo Comando Geral da Polícia Militar (PMERJ). 
Mesmo sem desvendarmos o "mito de ori-

Considerado por muitos como "homem de vanguarda”, o Cel. Cerqueira esteve empenhado em incorporar as temáticas de Direitos Humanos e prevençáo à violência à formaçáo policial, incentivando a tradução de trabalhos de referência nessas áreas, promovendo intercâmbios, atualizando os manuais de procedimento da corporaçáo e introduzindo o policiamento comunitário como uma estratégia privilegiada no controle da violência (ALBERNAZ; CARUSO; PATRÍCIO, 2007; RIBEIRO, 2014).

Há também os que identificam o programa das UPPs com as experiências de reduçáo da violência, realizadas na Colômbia. Em 2007, o governador Sérgio Cabral e o então Secretário de Segurança Pública, José Mariano Beltrame, integraram uma comitiva - formada por gestores e políticos de outros estados - que visitou as cidades de Bogotá e Medellín. Tal como anunciado pela imprensa à época, a visita teria como motivaçáo a busca por "soluçóes" para o cenário fluminense? 2 .

Por outro lado, há de se observar que o surgimento das UPPs foi também associado a motivações "não tão nobres", sendo interpretado como uma açáo pontual, dando suporte à realizaçáo dos eventos internacionais que aportariam na cidade, como a Copa do Mundo (2014) e os Jogos Olímpicos Rio-2016, ou ainda, como uma manobra de valorizaçáo imobiliária de áreas estratégicas então degradadas, como a Zona Portuária e setores da Zona Sul (área nobre da cidade) próximos a favelas. gem” (se é que há um, ou, "somente um”, deles) das UPPs, trataremos a experiência como uma alternativa à estratégia de "Guerra ao Tráfico", que marcara os primeiros anos do Governo $\mathrm{Ca}$ bral e as gestóes que o antecederam (MACHADO DA SILVA, 2010).

A despeito de não possuir diretrizes objetivas para sua implementaçáo - o programa só foi sistematizado em 2014, segundo o Boletim Interno da PMERJ 139/14 - é possível identificar um padráo nas ocupaçóes feitas pela polícia.

Conforme destacado por André Rodrigues e Raíza Siqueira (2012), o passo inicial da instalação das UPPs foi sempre uma intervenção tática, apoiada pela atuaçáo do Batalháo de Choque e do Batalhão de Operaçōes Especiais (BOPE), através do emprego de grande contingente humano e amplos recursos operacionais (veículos blindados, armamento pesado, canil, etc.), inibindo, assim, eventuais reaçóes por parte dos criminosos.

A segunda etapa, definida como "estabilizaçáo", seria marcada pela restriçáo dos acessos às comunidades - sendo comuns as abordagens a veículos e pedestres. "Ocorrem, nessa fase, rondas e intervençóes que visam à garantia do controle territorial, além das prisóes de criminosos remanescentes que [tivessem] manda[d]os expedidos" (RODRIGUES; SIQUEIRA, 2012, p. 11).

Por fim, na última etapa, há a instalaçáo fisica da unidade. Dá-se, nesse momento, também, a chegada dos "policiais novos", que viriam a ser jo-

2 Ver: <http://www.correiodobrasil.com.br/cabral-vai-a-colombia-em-busca-de-solucoes-para-a-seguranca/>. 
vens soldados, com pouco tempo de carreira (ou recém-formados), que integrariam uma cadeia de comando que pode ser resumida (grosseiramente) da seguinte forma: policiais "novos" envolvidos no policiamento comunitário/ostensivo e nas ações táticas se reportam a um supervisor (geralmente um sargento), que se reporta ao $\mathrm{Co}$ mandante da Unidade (geralmente um Capitão [ou Major]), que se reporta à Coordenadoria de Polícia Pacificadora (CPP), que se reporta diretamente ao Comando Geral da PMERJ.

Uma justificativa amplamente propalada para a utilizaçáo dos "policiais novos" era a expectativa de que esses fossem menos afetados pelos "vícios" da profissáo. Os chamados "vícios" podem ser entendidos como eufemismo de "suscetibilidade à corrupçáo".

Para além da plausibilidade (ou não) desse argumento, a verdade é que a instalaçáo das UPPs, provocou um aumento significativo das contrataçôes de policiais no Rio de Janeiro, o que secomprova pelo número de concursos públicos admissionais realizados entre os anos de 2009 e $2013^{3}$.

$\mathrm{O}$ interesse central desse artigo recai, exatamente, sobre esses "policiais novos", em particular sobre aspectos da sua formaçáo e no seu potencial de atuaçáo junto a outros operadores do poder público nas açóes de prevenção da violência.

\section{UPPs e Formação Policial: "policiais no- vos", "velhos paradigmas" ...}

Se por um lado havia o reconhecimento de que a utilização de quadros recém-formados era um acerto, por outro lado, tornavam-se evidentes os imbróglios ocasionados. Um deles é que o programa se estruturara sem planejamento prévio, a despeito do desenvolvimento das competências que seriam empregadas ou preconizadas no contexto deste modelo de policiamento.

$\mathrm{Na}$ verdade, os ditos "policiais novos”, que integrariam os quadros das UPPs, recebiam uma formaçáo praticamente idêntica aos policiais formados para atuarem no regime regular, lotados nos Batalhóes e nas suas respectivas Companhias Operacionais ${ }^{4}$.

Neste sentido, com a experiência das UPPs voltava à baila a discussáo - que assume o status de "problemática obrigatória" no campo dos estudos de segurança pública - (BOURDIEU, 2015) sobre o impacto da formaçáo sobre a atuaçáo policial.

Sem entrarmos na discussão acerca dos parâmetros de definiçáo do que, no limite, poderia se chamar de "cultura profissional policial" (O’NEIL; SINGH, 2007), vale sublinhar que a formaçáo do policial brasileiro tem sido vista por autores como Roberto Kant de Lima (2003), Paula Poncioni (2004) e Ana Paula Miranda (2008) como um aspecto central na relaçáo desenvolvida entre as instâncias de preservaçáo da ordem e da defesa (ou não) da democracia.

\footnotetext{
3 ver mais em: <https://ultimosegundo.ig.com.br/brasil/rj/2012-04-27/falto-de-recrutas-gera-boom-de-cursinhos-preparatorios-para-o-pm.html>. Acesso em: 13 out. 2018.

4 Companhios Operacionais são destacomentos dos Batalhões que visam aumentar a capilaridade e agilidade do patrulhamento ostensivo. Possuindo sede, efetivo e veículos próprios, o número de cias por Batalhão pode variar de acordo com a regiõo.
} 
Mesmo após o processo de redemocratizaçáo, culminado com a Constituiçáo de 1988, percebe-se que a formaçáo policial no Brasil segue marcada pela valorizaçáo do discurso autoritário e por um caráter fortemente hierarquizado, o que se processa em um "arranjo burocrático-militar" cujo foco é o enfrentamento do crime e do criminoso que, nesse contexto, termina por ser produzido, metonimicamente, como inimigo. Não restam dúvidas de que tais características não se harmonizam com o modelo de policiamento comunitário (MONTEIRO, 2016; GHIRINGHELLI, 2016).

Tal como destaca Luiz Antônio Machado da Silva (2010), ganhando grande espaço na mídia e insuflando esperança no enfrentamento da chamada "crise de segurança pública", as UPPs se apresentaram como oportunidade para um novo pacto entre polícia e comunidade, sugerindo uma relaçáo que só poderia ser sustentada pela lógica do respeito e da confiança.

Assim, no decorrer dos primeiros anos do projeto, tornaram-se rotineiras, nas páginas dos jornais cariocas, as iniciativas "simpáticas", promovidas pela Secretaria de Segurança, através dos Comandos das UPPs, direcionadas aos moradores de favelas. Bailes de debutantes ${ }^{5}$, distribuiçáo de presentes natalinos ${ }^{6}$ e visitas com crianças a estádios de futebol ${ }^{7}$ seriam apenas alguns exemplos das tentativas de aproximaçáo da polícia com os moradores, na expectativa do estabelecimento de uma atmosfera segura para a concretizaçáo do projeto.

Mesmo diante de tais esforços é evidente que o governo do estado tinha diante de si um desafio de grande monta: ajustar a formaçáo dos "policiais novos" às exigências das novas formas de integraçáo entre polícia e comunidade.

As iniciativas "simpáticas" e o apoio da mídia, certamente, eram condiçóes necessárias, mas não suficientes, para que um sentimento de confiança fosse prontamente construído. Se os policiais envolvidos no programa das UPPs eram "novos", as práticas, saberes e valores reproduzidos durante a sua formaçáo no Centro de Formaçáo e Aperfeiçoamento de Praças da Polícia Militar (CFAP) não necessariamente eram.

A reformulação da estrutura de formação policial no novo contexto também não se apresentava como uma tarefa das mais simples. Mesmo ações pontuais, como a revisão da grade curricular ou alteraçáo de conteúdos, seriam, possivelmente, atropeladas pelo ritmo da ampliaçáo do programa, haja vista que, entre 2009 e 2014, foram instaladas 38 UPPs no Rio de Janeiro, incluindo 02 destacamentos avançados na Baixada Fluminense.

5 Ver: MENDES, Wilson. "UPP providencia baile de debutontes." Jornal "Extro". Site. 03 dez. 2012. Disponível em: <https://extro.globo. com/noticios/rio/upp-providencia-baile-de-debutantes-6907069.html>. Acesso em: 01 out. 2018.

6 Ver: O DIA. "Comandante da UPP distribui presentes para crionças na Vila Cruzeiro." Site. 24 dez. 2014. Disponível em: < https://odia. ig.com.br/noticio/rio-de-joneiro/2014-12-24/comandante-da-upp-distribui-presentes-para-crioncos-no-vila-cruzeiro.html>. Acesso em: 01 out. 2018.

7 RIO DEJANEIRO (Estado). Alunos de projetos da UPP Camaristo Méier participam do Tour Maracanõ. UPP. Site. 2014. Disponível em: <http://www.uppri.com/index.php/ocontece/ocontece-selecionado/alunos-de-projetos-da-upp-camarista-meier-participam-do-tour-maraconae/camarista\%20meier >. Acesso em: 01 out. 2018. 
Soma-se a isso o fato de que alteraçóes dessa natureza deveriam adequar-se às diretrizes da Matriz Curricular instituída pela Secretaria Nacional de Segurança Pública (SENASP) em 2003, condiçáo que suscitaria reuniáo de recursos materiais e humanos que, dificilmente, seriam prontamente disponibilizados, tendo em vista as limitaçóes orçamentárias com as quais o programa conviveu, apesar da dimensão alcançada.

Há de se observar também, como bem aponta Miranda (2008), que a formação dos policiais fluminenses, realizada no CFAP guardava, em si, uma espécie de "vício de origem", tendo de conjugar dois princípios contraditórios: a obediência às regras e o respeito à disciplina, numa face, e a autonomia para identificar problemas e a iniciativa de propor soluçóes, noutra.

Esses dois princípios revelaram-se mais evidentes com o advento das UPPs. Instaladas em áreas historicamente desassistidas pelas políticas públicas, não tardou para que o efetivo policial estivesse envolvido em açóes que extrapolavam a manutençáo da ordem.

Como bem observa Cesar Pinheiro Teixeira (2015), em diversas oportunidades, era necessário que comandantes e tropa tivessem que "inovar", participando de projetos sociais (projetos esportivos e culturais, principalmente), sobretudo aqueles envolvendo crianças.

É plausível supor que décadas de relaçáo com tráfico e os abusos, recorrentes, cometidos pelas polícias em relaçáo aos moradores de favela contribuíssem para a recalcitrância de uma atmosfera de medo e suspeiçáo. Entretanto, as necessidades do dia a dia, por sua vez, haviam de impor algum nível de aproximação. Eis o desafio: construir junto aos novos quadros algum tipo de sensibilidade e proficiência que pudesse contribuir para essa integraçáo.

Cabe lembrar, também, que em pesquisa realizada pelo Centro de Estudos de Segurança e Cidadania da Universidade Cândido Mendes, publicada em 2015, registra-se uma progressiva percepçáo negativa dos policiais a respeito do seu preparo para atuar em UPPs. Em 2010, 36,9\% acreditavam estar despreparados para esse tipo de atuação. Em 2014, o número atingia 51,7 pontos percentuais. (MUSUMECI et. al, 2015).

\section{Curso de Cidadania e Acesso à Rede de Proteção Social para UPPs: antecedentes}

As expectativas construídas em torno do tema "pacificação" impeliram os meios acadêmicos e diversos setores da administraçáo pública a marcarem posiçáo sobre as UPPs. Não seria um exagero afirmar que o mesmo aconteceu com muitas das ONGs do Rio de Janeiro, que militam na área de segurança pública e defesa dos direitos humanos.

Talvez, o primeiro consenso produzido a respeito das UPPs tenha consistido na ideia de que somente a presença da polícia e o arrefecimento das ações do tráfico armado não seriam fatores capazes de sustentar o desenvolvimento socioeconômico dos territórios antes conflagrados e, tampouco, de garantir a inclusáo social dos seus moradores. Mais uma vez, estavam postas condiçóes necessárias, mas insuficientes.

Quase que como mantra, as autoridades, a mídia e estudiosos pareciam repetir o óbvio: havia a necessidade de implementaçáo imediata de programas específicos por parte do poder público (envolvendo preferencialmente a iniciativa 
privada e o terceiro setor) de modo a reverter décadas de descaso.

É bem verdade que no ano de 2010, houve um esforço do governo do estado, através da Secretaria de Estado de Assistência Social e Direitos Humanos, em concentrar os esforços dessa natureza, através do projeto da "UPP Social", que, muito en passant, poderia ser definido como um programa de açóes transversais destinadas a fazer convergir as iniciativas em segurança e outras políticas de desenvolvimento local, tendo como centro de gravidade a participaçáo popular.

Por questóes de rearranjos políticos que marcaram a corrida eleitoral daquele ano, o projeto terminou saindo do âmbito do governo do estado para ser desenvolvido pelo Instituto Pereira Passos, na esfera municipal, onde perdeu visibilidade.

Nesse contexto, outras instituições procuraram desenvolver uma relaçáo mais "orgânica" com a polícia militar ao longo desse processo, sendo observado o bypass da "UPP social".

Foi o caso da ONG Viva Rio, que com o apoio da Australian Agency for International Development (AUSAID), e em parceria com Coordenadoria de Polícia Pacificadora estruturou o Curso de Cidadania e Acesso à Rede de Proteção Social para Policiais Atuantes em UPP.

Este curso pode ser compreendido como resultado final de uma série de esforços empreendidos por esta organizaçáo junto à PMERJ, no que diz respeito à formaçáo policial.

Tendo uma militância de mais de vinte anos na área de segurança pública e defesa dos direitos humanos, a ONG Viva Rio nasce de um projeto maior, conhecido como Movimento Viva Rio, constituído ainda na década de 1990, em um momento de agudizaçáo da violência urbana no Rio de Janeiro, traduzido em dois episódios dramáticos: as chacinas da Candelária e de Vigário Geral.

Desde entáo, a organizaçáo procurou desenvolver um trabalho de apoio aos setores da PMERJ mais comprometidos com a valorizaçáo dos direitos dos cidadáos, e orientados por uma concepçáo de policiamento que se projetasse para além das práticas, eminentemente, repressivas.

No campo da formaçáa policial, pode-se mencionar o Curso de Aperfeiçoamento da Prática Policial Cidadã - CAAPC, a saber, uma experiência inovadora, concebida por um Coronel de polícia com formação em psicologia e desenvolvida pelos pesquisadores da ONG Viva Rio, no ano de 2002.

O curso procurava trabalhar situaçóes concretas do dia a dia policial, revisitadas em sala de aula a partir da reflexão sobre as consequências de açóes tecnicamente inadequadas ou dissonantes aos direitos individuais, tendo como eixos temáticos principais os referenciais do policiamento comunitário: ética policial; direitos de grupos vulneráveis, mediaçáo de conflitos e uso adequado da força.

Um dos méritos desse curso - concebido para a capacitaçáo de praças atuantes no patrulhamento ostensivo, principalmente - era o de romper com a estrutura hierarquizada e normativa (PONCIONI, 2004) que marca a formação militar, sugerindo uma experiência mais "horizontalizada”, tendo em vista que os instrutores 
eram todos sargentos, capacitados previamente por uma equipe de pesquisadores e educadores.

Em 2009, através de convênio firmado entre a ONG Viva Rio (através de seu braço jurídico para convênios governamentais, a OSCIP Viva Comunidade) e a Secretaria Nacional de Segurança Pública (SENASP), o projeto recebeu recursos federais, ampliando, assim, seu quadro de instrutores e instruendos, passando a ser direcionado também aos recrutas em formaçáo. Já em 2011, com o fim do convênio com o governo federal, o curso foi incorporado ao quadro de instruçóes regulares da formação de recrutas no CFAP pela Diretoria-Geral de Ensino (DGEI) da PMERJ.

Nesse mesmo ano, a ONG Viva Rio dá início a um curso experimental, intitulado Curso de Saúde Preventiva e Assistência à População em Areas Pacificadas, cujo objetivo era aprofundar a discussão, junto aos policiais atuantes em UPPs, sobre questôes relativas à qualidade de vida dos profissionais de segurança pública.

Com duraçáo de 24 horas semanais/turma, o curso envolveu cerca de 600 policiais recém-formados. A experiência preconizava discussóes nas seguintes áreas temáticas: (1) saúde fisica e emocional dos policiais; (2) drogas e reduçáo de danos; e (3) primeiros socorros. Além das disciplinas relacionadas à condiçáo profissional policial, existiam também aquelas orientadas à integraçáo desses com os moradores, sob a ótica da prevençáo à violência, como: (4) relaçóes de gênero e violência doméstica; (5) gestáo do espaço urbano; e (6) juventude(s) e sexualidade(s).

Ainda que os idealizadores da experiência a observassem como um "primeiro passo", num longo processo de aproximaçáo entre policiais e moradores de áreas pacificadas, o que se observava em sala de aula era a recalcitrância de velhos discursos: focalização/idealizaçáo do confronto; reproduçáo de estigmas referentes aos usuários de drogas; banalizaçáo da violência cometida contra moradores e, principalmente, a percepçáo de que "o saber da sala de aula" vale menos do "que o saber das ruas", reafirmando a lógica de que a profissáo policial é algo que se aprende na prática (KANT DE LIMA, 2004).

\section{o Curso de Cidadania e acesso à Rede de Proteção Social para policiais atuan- tes em UPPs: estruturação e metodologia}

O curso ora descrito foi concebido a partir de uma configuraçáo muito específica. Por um lado, a Coordenadoria de Polícia Pacificadora (CPP) procurava legitimar o trabalho nas UPPs como um segmento especializado do trabalho policial no Rio de Janeiro, dando vazáo ao projeto político da Secretaria de Segurança.

Logo, nada mais racional que esse "trabalho especializado" fosse embasado por uma formação que tivesse especificidades em relaçáo à formaçáo geral.

Até o momento (estamos falando do segundo semestre de 2012), o único programa de qualificaçáo regular específico fornecido aos policiais das UPPs era o Curso de Mediaçáo de Conflitos nas UPPs, estruturado a partir de uma parceria entre a PMERJ e o Tribunal de Justiça do Rio de Janeiro (MUSUMECI, 2014).

Quando a ONG Viva Rio sinaliza ao CPP a possibilidade de prolongar o processo de qualificaçáo dos policiais, diante dos recursos disponibilizados pela AUSAID, têm início os diálogos para a definiçáo do formato do que viria a ser o 
Curso de Cidadania e Acesso à Rede de Proteção Social para policiais atuantes em UPPS.

Uma das solicitaçóes feitas pelo chefe da CPP, na ocasiáo, foi que o curso tivesse alguma "dimensão prática”. Essa posição convergia com o interesse dos pesquisadores do Viva Rio, pois, em tese, dirimia o problema da suposta cisáo entre "retórica acadêmica" e "conhecimento prático".

Dessa forma, foi delineado um projeto onde os policiais tivessem, além das atividades de sala de aula, alguma vivência junto a outros atores institucionais diretamente envolvidos em processos de mitigaçáo de conflitos e prevençáo da violência. Referimo-nos, principalmente, aos chamados "operadores da ponta" dos serviços de assistência à populaçáo, como orientadores educacionais, operadores da rede de assistência social, conselheiros tutelares, entre outros.

As atividades em sala de aula teriam uma carga horária de 80 horas, divididas entre seguintes eixos temáticos: (1) Direitos Humanos; (2) Grupos Vulneráveis; (3) Policiamento de Proximidade; (4) Mediaçáo de Conflitos; (5) Relaçōes Interpessoais e Desenvolvimento Social; e (6) História e Gestão do Espaço Urbano.

O material didático utilizado foi um $M a n u-$ al de Instrução, elaborado pelos próprios professores do curso. $\mathrm{O}$ corpo docente era composto por pesquisadores de áreas como Ciências Sociais, Serviço Social, Direito, Psicologia e História, havendo também a participaçáo de oficiais da PMERJ, alguns deles com formaçáo nessas mesmas áreas.

No primeiro semestre de 2013, foi estrutu- rada uma "turma-piloto", sendo as aulas ministradas em um Centro Comunitário, no Morro da Fé/Sereno, no bairro da Penha. A iniciativa tinha a finalidade de verificar a receptividade dos alunos aos eixos temáticos e a dinâmica da interaçáo entre os policiais e os operadores da rede de proteçáo social. Nesta etapa foram capacitados 70 policiais das mais de 30 unidades instaladas até o momento.

No semestre seguinte, finalmente, foram iniciadas as atividades do Curso de Cidadania... na sede da Coordenadoria de Polícia Pacificadora (CPP), situada próximo ao Morro do Alemão. Contando com a participaçáo total de 218 alunos, provenientes das unidades e também por policiais da Força Nacional de Segurança (que atuavam com uma espécie de "UPP provisória", instalada no Morro Santo Amaro, na zona sul), o curso seguiu o delineamento inicial, tendo duas fases: uma em sala de aula ( 80 horas) e outra destinada à vivência com os operadores da rede de proteçáo social (80 horas).

Nessa última fase, seriam privilegiados os serviços mais próximos às estratégias de prevençáo da violência, como os Centros de Referência Especializados de Assistência Social (CREAS), os Centros de Referência da Mulher (que atende mulheres e crianças vítimas de violência doméstica) e os Centro de Atendimento Psicossocial para usuários de Álcool e Drogas (CAPsAD). A metodologia previa a realizaçáo de visitas técnicas, onde grupos de policiais travariam um contato com os operadores da rede no seu ambiente de trabalho, familiarizando-se, assim, com suas rotinas e tentando encontrar estratégias conjuntas de açáo.

Tanto as aulas como as visitas eram acompa- 
nhadas por monitores (também pesquisadores da área de humanas) que cuidavam das rotinas administrativas e logísticas e que orientavam os alunos na produçáo dos seus relatórios finais de atividade, servindo também como mediadores nas discussóes sobre as futuras estratégias de atendimento.

Por fim, cabe mencionar que os alunos respondiam a dois questionários: um no início e outro no final do curso. Esses "surveys" tinham como finalidade traçar o perfil social dos policiais, sondar seu grau de familiaridade com as comunidades e medir o impacto das aulas sobre seu conhecimento acerca da rede de proteçáo social.

Já nos primeiros contatos de sala de aula ficou claro que havia um clima de "desconfiança" por parte dos alunos em relaçáa ao curso, à sua participaçáo nele e ao projeto das UPPs, como um todo.

Quando provocados a falar sobre o arrefecimento dos confrontos entre a polícia e os traficantes, um dos alunos da turma-piloto sugeriu que depois das Olimpíadas "tudo voltaria ao normal", desacreditando claramente a longevidade do projeto das UPPs. Outro aluno questionou o interesse do investimento da AUSAID em um curso de formaçáo de policiais no Brasil, existindo também aqueles que tomavam o curso como uma espécie de puniçáo.

Como já havia ocorrido em outros projetos de formaçáo policial desenvolvidos pela parceria Viva Rio/PMERJ, ficava patente um alto grau de desinformação dos participantes sobre a natureza da atividade em que estavam inseridos, bem como os propósitos de sua participação.
Essa desinformaçáa, é claro, favorecia o surgimento de resistências, esvaziando, em certa medida, a experiência de sentido e aumentando o desgaste entre professores e instruendos em sala de aula.

A Coordenadoria de Polícia Pacificadora, diante desse cenário, procurou envolver mais intimamente os Comandantes das Unidades, de modo que os policiais chegassem um tanto mais "orientados" sobre os propósitos do curso e sua importância no âmbito geral do projeto. Todavia, talvezseja um exagero afirmar que a iniciativa tenha surtido pleno efeito.

Há de se frisar também que, ainda que tenham sido inegáveis os esforços dos policiais da CPP no intuito de vencer os "imponderáveis cotidianos", as dificuldades de ordem logística (falta de espaço adequado para as aulas - sendo algumas ministradas no refeitório do CPP, problemas com equipamentos, etc.) foram também recorrentes, o que pode ter reforçado a imagem da experiência como uma iniciativa pró-forma.

\section{Perfil dos participantes e sua familiari- dade com a rede de proteção social}

A partir da análise do material citado na introdução, sobre o perfil dos alunos podemos afirmar que o curso foi composto por um público de policiais recém-formados ou em início de carreira: apenas 9\% dos alunos tinham mais de cinco anos na polícia militar.

Tratava-se também de um público com alto grau de escolaridade. Sessenta por cento dos alunos havia ingressado no ensino superior, sendo que $29 \%$ dos alunos já havia concluído a graduaçáo. 
No que diz respeito à familiaridade com o ambiente de trabalho, 30\% dos alunos afirmaram que, até o ingresso na carreira, nunca haviam estado em uma favela; $35 \%$ afirmaram conhecer muito pouco as favelas e seus moradores e 14\% informaram que conheciam muitos moradores de favelas, mas que tinham pouco conhecimento sobre o cotidiano dessas comunidades.

A respeito do conhecimento da rede de proteçáo social, 54,4\% dos alunos respondeu que não sabiam quais eram as atribuiçóes dos Centros de Referência de Assistência Social e 13,7\% não conseguiram definir se realmente sabiam ou não (sic). $\mathrm{O}$ desconhecimento sobre os serviços ligados ao atendimento de usuários de drogas era ainda maior. Noventa e três por cento dos consultados não conhecia a sigla $\mathrm{CAPSAD}$, referente ao Centro de Atendimento Psicossocial para Álcool e Drogas. O mesmo se deu em relaçáa ao Centro de Referência Especializado de Assistência Social: 90\% dos alunos afirmou não conhecer o significado da sigla CREAS.

Uma dimensáo altamente relevante na análise dos números citados é que os Centros de Referência da Assistência Social (CRAS) e os Centros de Referência Especializados da Assistência Social (CREAS) são órgãos municipais com grande poder de capilaridade, orientados, sobretudo, para o acompanhamento de familias e de indivíduos em situaçáo de vulnerabilidade. O CREAS, inclusive, opera uma rede especializada, dando suporte às situaçóes que envolvem violaçáo de direitos, incluindo as práticas de violência em suas diversas modalidades, sendo indusive responsável pelo acompanhamento de crianças e adolescentes envolvidos em crimes de pequeno potencial ofensivo. Sendo as UPPs um projeto voltado para o policiamento de proximi- dade e baseado na prevençáo da violência, podemos dizer que, "no mínimo", chama a atenção o nível de desconhecimento dos policiais sobre a existência e as missóes institucionais desses serviços. O mesmo se aplica ao CAPsAD que, sendo um serviço da saúde voltado para o atendimento de usuários abusivos de álcool e drogas, teria, em tese, grande interface com operadores do sistema jurídico-policial, sobretudo em tempos de ampliaçáo da discussáo sobre a descriminalização do uso de entorpecentes e de sistemático enfrentamento da violência doméstica, largamente associada ao abuso de álcool e outras drogas.

\section{Os dilemas da aproximação entre polícia e a rede de proteção social}

Indiscutivelmente, o desconhecimento por parte dos policiais acerca do trabalho dos operadores da assistência se apresenta como um obstáculo na tentativa de construçáo de ações integradas entre essas instâncias do poder público e, neste sentido, iniciativas como a do Curso de Cidadania... seriam salutares.

Todavia, os limites da integraçáo entre a polícia e a rede de proteçáo social talvez não se encerrem no plano da falta de informaçáo e a primeira reuniấo entre pesquisadores do Viva Rio e os operadores da rede de proteçáo revelam dimensóes interessantes sobre isso.

Esse encontro, realizado no Morro da Fél Sereno, pouco antes do início das atividades de visita, tinha como objetivo "sensibilizar" alguns dos técnicos da rede de proteçáo social da região da Penha (onde foi realizado o curso-piloto) a respeito da importância da entrada dos policiais das UPPs no circuito de encaminhamentos de casos que extrapolassem o âmbito criminal, stricto senso. Mais que isso, o objetivo das reunióes era a discussáo sobre o processo de legitimaçáo das 
polícias como um integrante dessa rede.

As operadoras técnicas da rede de assistência, por sua vez, deixaram claras suas preocupaçóes que, apesar de parecerem bastante pragmáticas, resumiam bem o melindre da ação em conjunto com a polícia no seu cotidiano. "Os policiais realizariam as visitas uniformizados"? "Seriam levados até os locais da visita em viaturas descaracterizadas"?

A preocupação era fundamentada pelo fato dos serviços de assistência englobarem moradores que por motivos diversos eram avessos ao contato com a polícia. Fosse por violências sofridas no passado, fosse por simples convicçáo ou mesmo pelo fato de estarem, eles próprios, envolvidos com alguma atividade ilícita ou terem parentes nessa condiçáa. Ficou claro naquele encontro que a relaçáo entre a rede de assistência local e a polícia era algo que precisaria ser manejado com muita cautela.

Os advogados, psicólogos e assistentes sociais que compóem o quadro de street level bureaucracy dos serviços de atenção social (LIPSKY, 1969), por força de seu trabalho, terminam sendo "guardiōes" de muitas narrativas e acontecimentos que, definitivamente, aos olhos de seus atendidos, não deveriam jamais chegar aos ouvidos da polícia. Seu universo de atuaçáo é um terreno onde a polícia, não raro, está ausente ou é evitada. Assim, a aproximaçáo teria de ser feita de modo a não colocar os operadores da assistência sob suspeita, perante a comunidade.

No caso do Curso de Cidadania... as orientaçóes foram seguidas criteriosamente. Os policiais realizaram as visitas técnicas à paisana e em horários de baixa frequência para interferir o mínimo na rotina de trabalho. Há de se ressaltar também que as visitas, por questóes logísticas, foram realizadas em unidades de atendimento situadas em regióes mais centrais, ou seja, fora do ambiente das comunidades.

Os cuidados e etiquetas sinalizados nesse encontro inicial levantam algumas questóes: qual o grau de permeabilidade dos serviços de proteçáo social às polícias como um ator relevante de sua rede institucional? Qual a disponibilidade e interesse das polícias em construir legitimidade para atuação em uma arena que, historicamente, não éa sua?

Temos de reconhecer que há uma ampla discussáo sobre o papel das políticas de âmbito comunitário na prevençáo da violência (BEATO, 1999; BAYLEY; SKOLNICK, 2001; MESQUITA NETO, 2004). No caso brasileiro, esse processo aparece intimamente ligado à consolidação do sistema de seguridade social e à capilarizaçáo dos recursos de assistência - fortalecida pelo maior protagonismo dos municípios -, no contexto pós-Constituiçáo de 1988. Contudo, há um longo caminho a trilhar, em termos de agenda de pesquisa, no que diz respeito a processos de integraçáo entre polícias e atores da rede de proteçáo. Caberia aprofundar as nuanças das experiências em curso, tendo como perspectiva, sobretudo, as estratégias de quebra das resistências, de ambos os lados. No momento, dado os limites de profundidade do presente artigo, contentamo-nos em tomar o tema como promissor, ao passo que se consolidem as políticas de segurança, efetivamente, comprometidas com a prevençáo da violência e engajadas a açóes que se projetem para além da díade repressão/punição.

\section{Forças e fraquezas de um encontro ou considerações finais}


É preciso compreender que iniciativas como o Curso de Cidadania... sáo experiências que têm uma dimensáo instrumental, mas também uma dimensão políica.

Como sublinhamos, o projeto das UPPs foi uma experiência que se iniciou antes mesmo de ter seus marcos institucionais definidos. No ano em que completam dez anos da instalaçáo da primeira unidade é dificil afirmar qual o futuro do projeto, bem como os avanços sociais com ele obtidos e, se eles existem, quais os parâmetros adequados de avaliaçáo.

O que se pode afirmar com alguma segurança é que iniciativas heterogêneas terminaram por convergir, imprimindo às UPPs um caráter de "esperança última” ou de "alternativa eficiente" ao desgastado modelo de "Guerra ao Tráfico", táo conhecido pelos moradores do Rio de Janeiro (MACHADO DA SILVA, 2010).

Assim, alinhar-se ao projeto das UPPs, num sentido muito específico, foi alinhar-se ao discurso de que o enfrentamento, estritamente bélico, do tráfico de drogas nas favelas fracassou e que formas outras de encarar o problema precisa(va) $\mathrm{m}$ ser encontradas, para além das intervençóes táticas sazonais e desarticuladas, que vitimam, diariamente, moradores e policiais.

Entram em cena, então, os desafios impostos pelas práticas preventivas - que não sáo poucos. Consideremos, aqui, apenas dois aspectos mais ajustados aos argumentos em curso.

Em primeiro lugar, a "prevençáa”, na cosmologia dos nossos policiais, constitui-se numa antítese de "repressáo" (uma metáfora de efetividade e autoridade) e de "açáa" (no sentido do confronto armado) que sáo a base do ethos produzido nas academias de polícia (MACHADO; ALBUQUERQUE, 2001).

Em algumas ocasióes foi possível registrar relatos dos alunos afirmando que mesmo os moradores faziam uma distinçáo entre "o policial de UPP" e "o policial", denotando que o trabalho de policiamento de proximidade fosse, por assim dizer, uma espécie de "serviço de apoio" (serviço menor não seria um termo exagerado, certamente) do policiamento exercido pelos batalhōes (em particular o BOPE).

Se nas representaçóes coletivas, as atribuiçōes regulares do papel da polícia é a realizaçáo de prisóes e o confronto armado, o policial que "auxilia e previne", que "medeia e dialoga” não seria, assim, exatamente um policial!

O segundo aspecto a ser destacado é que as açôes de prevenção da violência se viabilizam a partir de uma soma de esforços que passa, necessariamente, por açóes intersetoriais do poder público e por algum nível de envolvimento da sociedade.

Seja no Brasil, seja em outros países (como o caso do cease fire de Boston) (BEATO, 1999), açóes exitosas no campo da prevençáo da violência registraram, recorrentemente, o envolvimento de projetos sociais e instâncias governamentais relacionados a alguns temas: gestáo urbana, atençáo à juventude, programas de atençáo ao abuso de drogas, mediaçáo de conflitos, inclusáo social e ampliaçáa de oportunidades, sistematizaçáo de informaçôes sobre a incidência criminal em nível local, etc.

Não por acaso esses temas fizeram, em maior 
ou menor grau, parte do quadro de disciplinas do Curso de Cidadania..., e também, talvez não por acaso, o contato com a rede de proteçáo social nos tenha surgido como saída para a demanda do Comando das UPPs, que buscava dar ao curso um caráter mais prático.

Como vimos, o grau de desconhecimento dos policiais atuantes nas UPPs sobre o papel institucional dos órgãos que compóem a rede de proteçáo era acentuado. Teoricamente as horas em sala de aula amenizaram essa deficiência e ao final do curso $87 \%$ dos alunos que responderam ao questionário final afirmavam conhecer as atribuiçōes do CRAS, apenas 16,6\% não sabiam ainda o que significava a sigla CAPSAD e só 36\% ainda desconheciam o CREAS.

A despeito desse pequeno progresso os policiais demonstravam-se ainda muito céticos em relaçáo à integraçáo das suas rotinas às da rede de proteçáo social. Numa aula ministrada com a presença dos Comandantes e subcomandantes de unidade, um relato nos chamou atenção. Um policial descreveu uma situação onde atendera um chamado onde uma criança havia sido abandonada. Contou que ficou horas com ela dentro da viatura a procura do Conselheiro $\mathrm{Tu}$ telar do bairro para realizar o encaminhamento sem sucesso. A pergunta uníssona foi: "E esses órgáos funcionam?”

Em linhas gerais a percepção dos policiais sobre órgáos da rede de proteçáo, nessa oportunidade, remontava o imaginário que muitos brasileiros têm sobre órgáos governamentais em geral: os serviços funcionam poucas horas por dia, há poucos funcionários para muitos casos $\mathrm{e}$ as necessidades das pessoas que procuram esses serviços extrapolam, amplamente, os recursos disponíveis.

Ainda que 60\% dos alunos tenham reconhecido as abordagens do curso como "muito pertinentes" ao seu trabalho cotidiano, é dificil dimensionar o que essa experiência e experiências análogas signifiquem para eles. Essa é uma questão instigante para pesquisas futuras.

O que podemos afirmar, a partir da análise empreendida, é que parece haver ainda um longo caminho a percorrer, no que diz respeito à integraçấo das açóes policiais às da rede proteção social.

Os meses de convivência com os policiais, com os monitores e com os instrutores do curso levam a crer que o uso da autoridade e da força sáo ainda referenciais muito sedimentados nas representaçôes dos alunos sobre sua própria profissáo.

Conforme sinaliza Poncioni (2004; 2013), os esforços empreendidos nos últimos vinte anos pelo governo federal, sobretudo através da SENASP, com iniciativas como a criaçáo da Rede de Altos Estudos em Segurança Pública (Renaesp), os programas de bolsa-formaçáo - que incentivam qualificação técnica e profissional dos policiais, através de cursos presenciais ou on-line - e a criaçáo da Matriz Curricular Nacional para o ensino policial, colidem com estruturas de formaçáo policial marcadas pela não profissionalizaçáo do quadro de instrutores, pela presença de materiais didáticos obsoletos, pela ausência de ambientes e horários que favoreçam ao estudo e por uma concepçáo do trabalho da polícia como "combate ao crime", "empregando-se frequentemente o uso intensivo de táticas e procedimentos de guerra" (PONCIONI, 2013, p. 53). 
É claro que a experiência das UPPs terá sua história escrita por forças que vão muito além do tema formaçáo/profissionalizaçáo dos policiais militares. O período pós-Jogos Olímpicos, marcado pela intensificaçāo dos confrontos com traficantes, pela crise econômica que culmina na "Falência" do estado do Rio de Janeiro e pela crise política que culmina na prisáo do ex-Governador Sérgio Cabral, ratifica essa ideia.

Entretanto, retomando os ensinamentos de J. Skolnick e D. H. Bayley (2001), faz-se mister compreender que, num futuro próximo ou em tempos mais distantes, o sucesso das experiências

\section{Referências Bibliográficas}

ALBUQUERQUE, Carlos de Linhares de; MACHADO, Eduardo Paes (2001). "Sob o signo de Marte: modernização, ensino e ritos da instituição policial militar". Sociologias, ano 3, nº 5, jan/jun 2001: 214-237.

ALBERNAZ, Elizabete; CARUSO, Haydée, PATRÍCIO, Luciane (2007) "Tensões e Desafios de um Policiamento Comunitário em Favelas do Rio de Janeiro: o caso dos Grupamentos de Áreas Especiais". São Paulo em Perspectiva, n.2, v.21.

BAYLEY, D.; SKOLNICK, J. Nova Polícia: Inovações nas Polícias de seis cidades norte-americanas. São Paulo. Edusp, 2001.

BEATO, Claudio (1999). Políticas públicas de segurança e a questão policial. São Paulo em Perspectiva. vol.13 no.4

BOURDIEU, Pierre (2015). A Economia das trocas simbólicas. Tradução Sérgio Miceli. 8.ed, São Paulo, Perspectiva. de prevençáo à violência dependerá sempre do envolvimento da comunidade e dos atores institucionais não-policiais no planejamento e avaliação das políticas de segurança.

Para tanto é preciso que essas ideias sejam trabalhadas, discutidas e valorizadas na formação policial. Caso contrário, iniciativas como o Curso de Cidadania e Acesso à Rede de Proteção Social para policiais atuantes em UPPs se perpetuaráo como ações necessárias, mas sempre insuficientes para a construçáo de um paradigma que náo seja exclusivamente repressivo.

CABRAL, Sérgio. Versão na Integra do Discurso de Posse. O GLOBO, Rio de Janeiro, 04 nov. 2011. Disponível em: <https://oglobo.globo.com/rio/confira-integra-do-discurso-do-governador-sergio-cabral-na-cerimonia-de-posse-2844108>. Acesso em: 01 out. 2018.

DAMATA, Roberto. Relativizando: uma introdução à antropologia social. 6. ed. Rio de Janeiro: Rocco, 2000.

GHIRINGHELLI, Rodrigo (2016). Formação e modernização da atuação policial. in V. Garcia (Org.) Convivência e Segurança cidadã: reflexões por uma nova abordagem de segurança pública, Brasília: PNUD/Conviva.

KANT DE LIMA, Roberto (2003). "Direitos Civis, Estado de Direito e "Cultura Policial": a formação policial em questão". In: Revista Brasileira de Ciências Criminais, $n^{0}$ 41. São Paulo, Editora Revista dos Tribunais, jan-mar, p. $241-256$.

LIPSKY, Michael (1969). Toward of Street-level Bureaucracy. Institute for Research of Poverty, n.1, v.1: 48-69. 
MACHADO DA SILVA, Luiz A. (2010). Afinal, qual é a das UPPs. Rio de Janeiro: Observatório das Metrópoles.

MESQUITA NETO, P. Prevenção do Crime e da Violência e Promoção da Segurança Pública no Brasil. In: Arquitetura Institucional do Sistema Único de Segurança Pública. SENASP, 2004.

MIRANDA, Ana Paula M. (2008). Dilemas da Formação Policial, Treinamento, Profissionalização e Mediação. Educação Profissional: Ciência e Tecnologia, n.1, v.3: 67-76.

MONTEIRO, Fabiano Dias; ARAUJO, Jonas Pereira; SANTOS, Sandro Costa (2015). "Estratégias de Policiamento, Inclusão Social e Enfrentamento da violência: as experiências do Rio de Janeiro, Salvador, Curitiba e cidade do Panamá". Relatórios Viva Rio, n.1, v.1: 8-29. Disponível em: <http://www.vivario.org.br/wordpress/wp-content/uploads/2017/07/Cadernos-Viva-Rio-1-2015. pdf>. Acesso em: 01 out. 18.

MONTEIRO, Fabiano Dias (2016). "Formação Policial, Polícia e Direitos Humanos" in V. Garcia (Org.) Convivência e Segurança Cidadã: reflexões por uma nova abordagem de segurança pública, Braślia: PNUD/Conviva.

MUSUMECl, Bárbara. (2014). Mediação de conflitos nas UPPs: sistematização de uma escuta. Disponível em: <http://www.ucamcesec.com.br/textodownload/2-mediacao-de-conflitos-nas-upps-sistematizacao-de-uma-escuta/>. Acesso em: 01 out. 18.

MUSUMECI, B; MUSUMECI, L.; RAMOS, S (2015). UPPs: 0 que pensam os policiais? Disponível em: <https://www.ucamcesec.com.br/wp-content/ uploads/2015/12/1449178471_magicfields_arquivo_1_1.pdf >. Acesso em: 13 out. 18.
NIJ. National Institute of Justice. Program Profile: Operation Ceasefire (Boston, Mass.). Site. 2011. Disponível em: $<$ https://www.crimesolutions.gov/ProgramDetails.aspx?|D=207>. Acesso em: 01 out. 18.

O'NEIL, Megan; SINGH, Anne-Marie (2007). Introduction, The Police Occupational Culture: New Debates and Directions, M. O'Neill, M. Marks, and A. Singh (eds.), Emerald/Elsevier Press.

PONCIONI, Paula (2004). Tornar-se policial: A Construção da Identidade Profissional do Policial no Estado do Rio de Janeiro. Tese de Doutorado, Departamento de Sociologia, Faculdade de Filosofia, Letras e Ciências Humanas, Universidade de São Paulo, mimeo.

PONCIONI, Paula (2013). Governança democrática da segurança pública. Civitas, Porto Alegre, v. 13, n. 1: 4855.

TEIXEIRA, Cesar Pinheiro (2015). 0 'policial social': Algumas observações sobre o engajamento de policiais militares em projetos sociais no contexto de favelas ocupadas por UPPs. Dilemas: Revista de Estudos de Conflito e Controle Social - Vol. 8 - no 1 - JAN/FEV/MAR - pp. 77-96.

RIBEIRO, Ludmila (2014). 0 nascimento da polícia moderna: uma análise dos programas de policiamento comunitário implementados na cidade do Rio de Janeiro (1983-2012). Análise Social, 211, XLIX (2º), p. 272-309.

RODRIGUES, André; SIQUEIRA, Raíza (2012). "As Unidades de Polícia Pacificadora e a Segurança Pública no Rio de Janeiro". Comunicação do ISER, n.67, v.31: 9-52. 



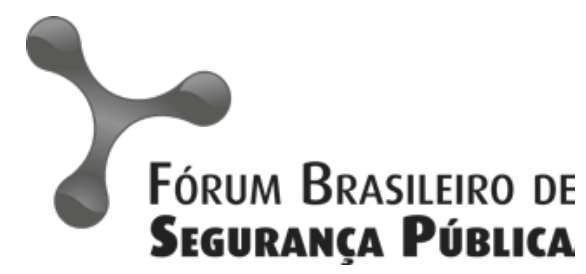

ISSN 1981-1659 